
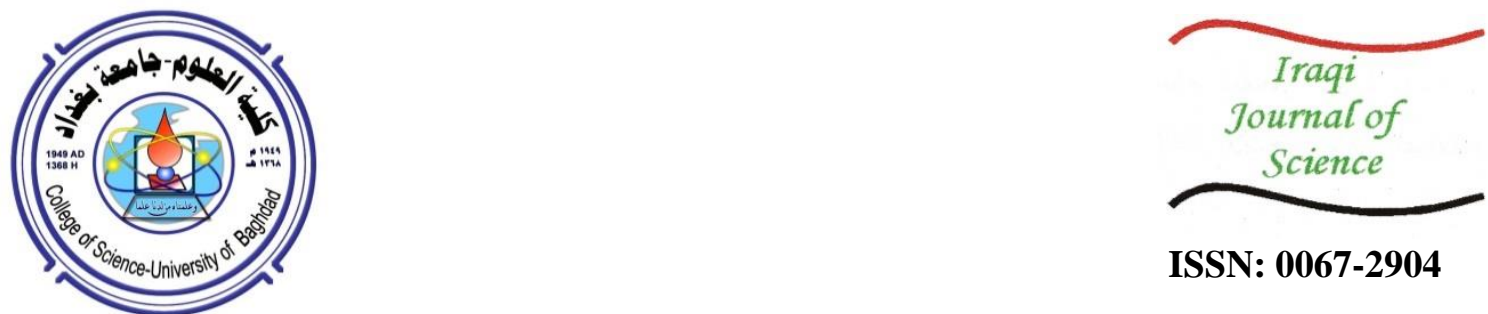

ISSN: 0067-2904

\title{
Forest Change Detection in Mosul Province using RS and GIS Techniques
}

\author{
Faisel G. Mohammed ${ }^{1}$, Maryam H. Ali ${ }^{1}$, Sajaa G. Mohammed ${ }^{2}$, Hiba S. Saeed ${ }^{3}$ \\ ${ }^{I}$ Department of Remote Sensing \& GIS, Collage of science, University of Baghdad, Baghdad, Iraq \\ ${ }^{2}$ Department of Mathematics, Collage of science, University of Baghdad, Baghdad, Iraq \\ ${ }^{3}$ Scientific affairs, Collage of science for women, University of Baghdad, Baghdad, Iraq
}

Received: $21 / 8 / 2020$

Accepted: 10/4/2021

\begin{abstract}
There are many events that took place in Al Mosul province between 2013 and 2018. These events led to many changes in the area under study. These changes involved a decrease in agricultural crops and water due to the population leaving the area. Therefore, it is imperative that planners, decision-makers, and development officials intervene in order to restore the region's activity in terms of environment and agriculture. The aim of this research is to use remote sensing (RS) technique and geographic information system (GIS) to detect the change that occurred in the mentioned period. This was achieved through the use of the ArcGIS software package for the purpose of assessing the state of lands of agricultural crops and forests. Normalized Difference Vegetation Index (NDVI) and Normalized Difference Moisture Index (NDMI) were adopted in the current calculations. This can help the decision-maker take the necessary measures to avoid the problems caused by the emergency events. The results obtained through this research showed that the region had rate changes in farms, water, and forests of about $1 \%$, as it was found that there was a decrease in the level of the Tigris River and an increase in the area of carrot crop farms. Also, the results indicated a decrease in areas of agricultural crops in specific regions, while they increased in others.
\end{abstract}

Keywords: Remote sensing; NDVI; image classification; satellite images; GIS.
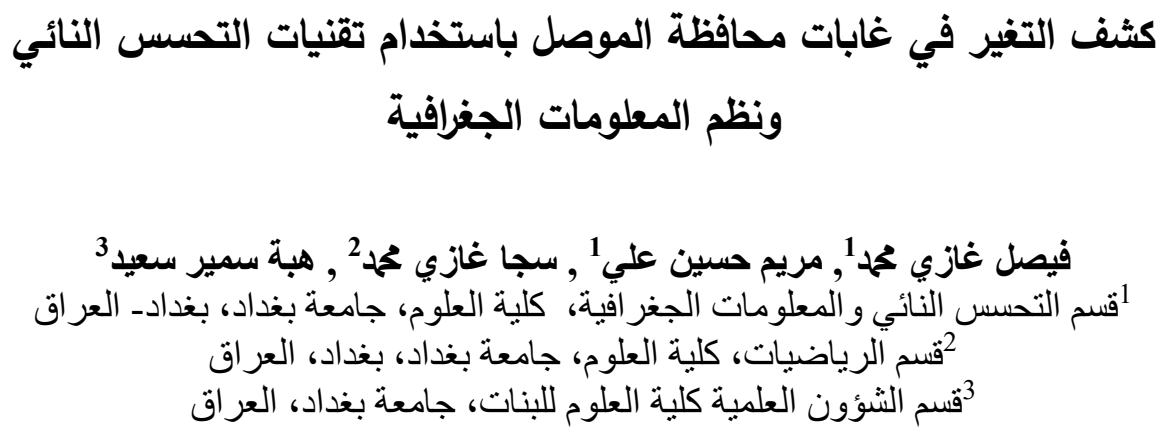

*Email: faisel.mohammed@sc.uobaghdad.edu.iq 


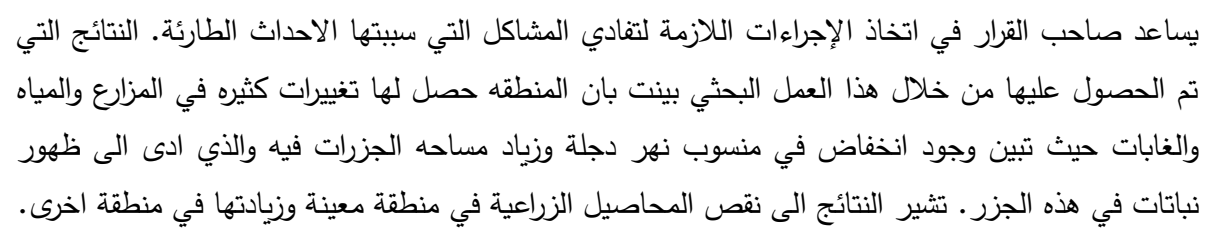

\section{Introduction}

\subsection{Background}

The general objective of this research work is to exploit the capacity of geographic information systems (GIS) technology in managing forests in general in the Mosul Governorate, northern Iraq. GIS techniques have dominated nearly every field of engineering, natural, and social sciences, providing accurate, effective, and reproducible methods for collecting, presenting and analyzing spatial data. Mosul forests are a dynamic resource, as they are affected by many symbiotic environmental processes and direct management interventions. To make a better decision to improve productivity and save time, money, and manpower in forest management activities, dynamic descriptive and site inventory data are required not just geographic information. The development of geographic information systems, global positioning system (GPS), and remote sensing (RS) technologies have allowed field data to be collected and analyzed in ways that were not possible before the arrival of computers. GIS has proven to play a vital role in public resource management, crop harvest planning, fire management, map production, and strategic planning and modeling. The range of applications reviewed in this paper is a clear evidence of the great value of forests and the potential of geographic information systems to aid in their management. Despite the diversity of applications, a number of general conclusions could be drawn about the role of GIS in the forest sector [1-8]. The main objective of the present study is to estimate the forest area and its changes over time. The specific objectives include: i. To assess and evaluate forest and forest cover changes using digitized satellite imagery and ground assessment, ii. To add new dimensions to up-dating maps by using the method of remote sensing as a tool for monitoring of the change, iii. To develop methods based on the results obtained that may help in future forest planning in the region, iv. To provide tools that facilitates forest management on sustainable basis.

\subsection{Related Works}

There are many different related previous works related to the current research topic, which could be summarized as in the following paragraphs.

In 2013, M. A. Ahmed and W. A. Ahmad, adopted the Normalized Difference Vegetation Index (NDVI) adopted as practical tool for monitoring the surrounding area of Himreen Lake $\left(34.1911^{\circ} \mathrm{N}, 44.995^{\circ} \mathrm{E}\right)[1]$.

In 2016, I. J. Muhsin presented a method to detect the most important changes in Baghdad city vegetation. Registration and rectification of the two original images (in 2000 and 2014) were the first preprocessing steps applied in her study. Change detection was computed using the subtractive NDVI approach. Subtraction between the bands of the two images and the ratio of the red to blue bands were also computed. Change detection mask was also used to compute the changes between the resultant classes, by employing the minimum distance classification or detection after classification. Many statistical properties of the original and processed images were illustrated, including image detection, NDVI, image classification, and image subtraction [2].

In 2017, I. J. Muhsin and A. H. Mohammed, monitored the changes in the studied area (Karbala province). Several image processing methods, such as supervised classification using maximum likelihood classifier and support vector machine classifier, were applied. Target detection using matching filter and change detection using subtractive method were also used to detect the change in vegetal cover of the studied area. Many histograms and 
statistical properties were illustrated. also, the pixel count and the target area were computed [3].

\subsection{Problem Statement}

The importance of major forests lies in their ability to maintain the ecological balance. Paying attention to the natural resources of forests and preserving the quality of forests and their water enhance their sustainability as important nutritional and economic sources [6]. As it was known previously, the forests of Mosul are distinguished by greenness and prosperity The main problem in forest management is how to deal quickly, Consistent, versatile, accurate, cost-effective, and up-to-date information [7]. Despite the scarcity of data, we obtained images that cover the period between 2013 and 2018. After analyzing these images, we showed the amount of damage that occurred in the forests of Mosul, from the deforestation to the scarcity of water of the Tigris River, which is the main water source in the area. Thus, necessary measures should be taken by the competent authorities for these forests to return to their previous states of environmental and economic values for the region [8].

\section{Study Area}

Mosul's forests are located at $36.35^{\circ} \mathrm{N} 43.15^{\circ} \mathrm{E}$ (left coast of the city). The forests were given the name of the Hadba Model Forest in 1954, when they occupied an area of 10 dunums. A limited-capacity nursery was established to produce seedlings of forest trees. The work continued until 1955 and around 200 acres were planted on the eastern bank of the Tigris River in the northern side of the city. The forests expanded in stages until they reached an area of 900 acres. Various types of trees were planted such as eucalyptus, spender, elm, pine and other types and varieties that suit the environmental conditions of the city. This forest was at best condition until the mid-eighties of the twentieth century, when some areas were deducted from it to establish some facilities.

In 2017, large parts of the forests were attacked "during the war against the ISIS in Iraq and Syria", and the Nineveh civil defense teams were able to control the fire caused by this attack [9]

At the present time, we have not noticed any development activities in the forests, such as attempts of rehabilitation or any other measures to enhance its current conditions[10]. Figure 1 shows the study area, which appears as outlined by a red polygon.

The Forest / Mosul Park
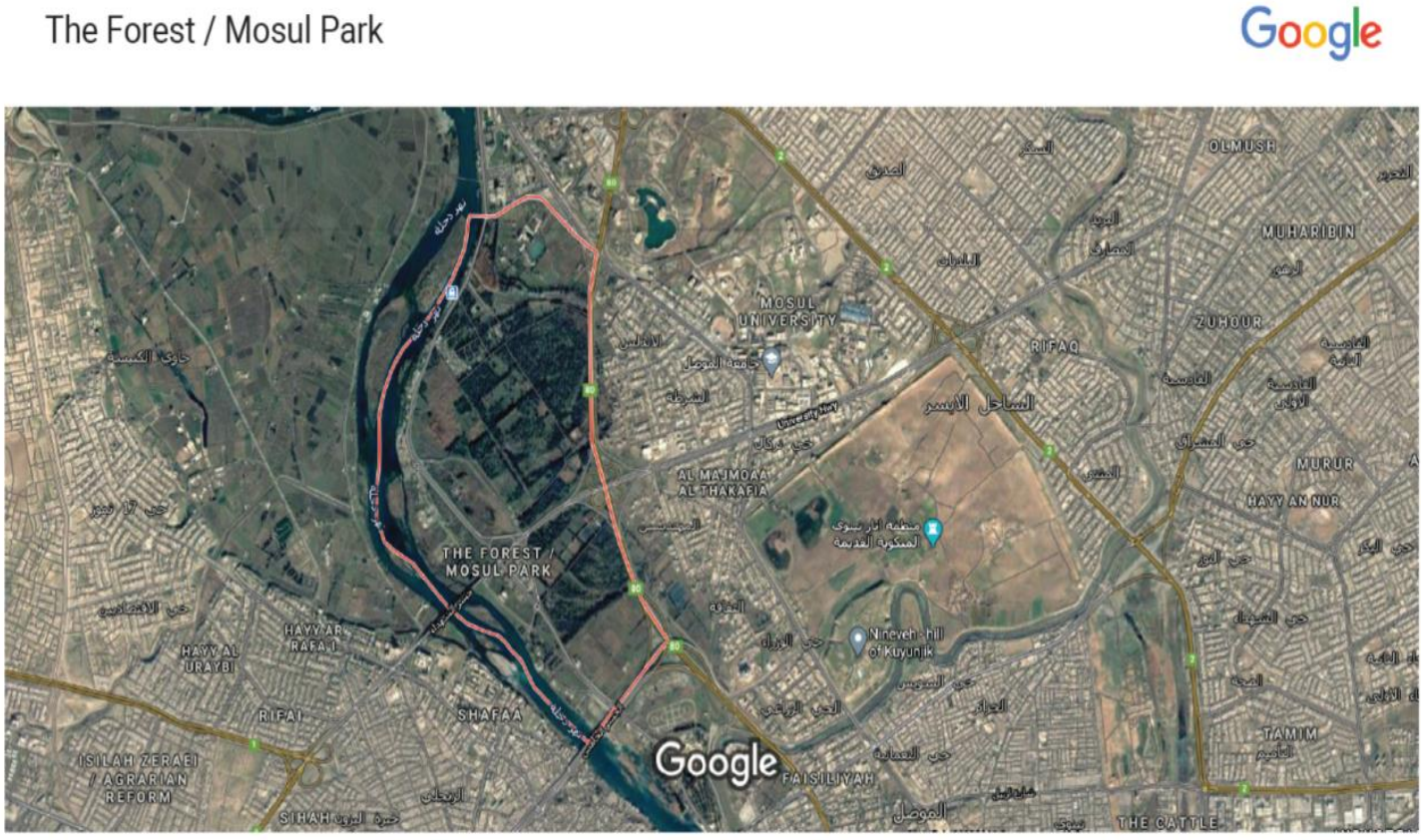

Google

Figure 1- The study area.

\section{Change detection method}


Change detection is the process of identifying differences in the status of a particular object or phenomenon for different periods of times [8]. The change in land and its cover has become a key component of current studies and procedures for natural resource management and observing environmental changes. The rapid development of plants cover mapping has led to increase studies of land use and land cover change worldwide. The terms land use and land cover are often used alternately; the term land use refers to all human activities that arise on Earth's surface (How land is used; e.g. residential buildings or agricultural crops), whereas land cover refers to the natural and physical specifications or artificial specifications of Earth's surface. To create a land-use map by using satellite data, image classification is an effective way to extract information [11]. Understanding enough of the characteristics of landscape, and imaging systems and information uses the relevant extraction methodology for analysis depends on the successful use of satellite remote sensing for land use / discovering of land cover change. Information is obtained either through extracting it from remote sensing data or visiting the sites on the ground. The detected changes often reflect the effects of nature and human activities from different time images. Remote sensing has brought about a major technological breakthrough in the way of collecting information on land resources, ocean resources, forests, agriculture and others. Studies have shown the effectiveness of using remote sensing data as a powerful tool for detecting land-use changes in critical environmental areas, plant cover dynamics, and urbanization expansion[12].

In the current work, satellite images were pre-processed before classification by using the histogram modification method to improve image quality and achieve better classification accuracy.

In supervised classification, specific wave spectra from specific locations in the image are used. These specified sites are given the generic name "Training Sites", and they are userselected. Typically, the vector layer is numbered with a rasterized scene. The vector layer consists of different polygons.

\section{Design and Research Method}

The three primary colors of light are blue, green, and red (RGB). With a different base color for each range, computer screen can display a picture from three different scales. When we add those three images, the result will be one color image, with the color of each pixel being determined by the different brightness RGB groups [13,14]. Table 1 shows the technical information of the original image.

Table 1- Technical Information of original image

\begin{tabular}{|c|c|}
\hline Product & Geo Tiff format \\
\hline Satellite/Sensor & Landsat 8 OLI \\
\hline Resolution & 30 meters \\
\hline Coverage & $180 \times 180 \mathrm{KM}$ \\
\hline Acquisition Date & 2013 and 2018 \\
\hline
\end{tabular}




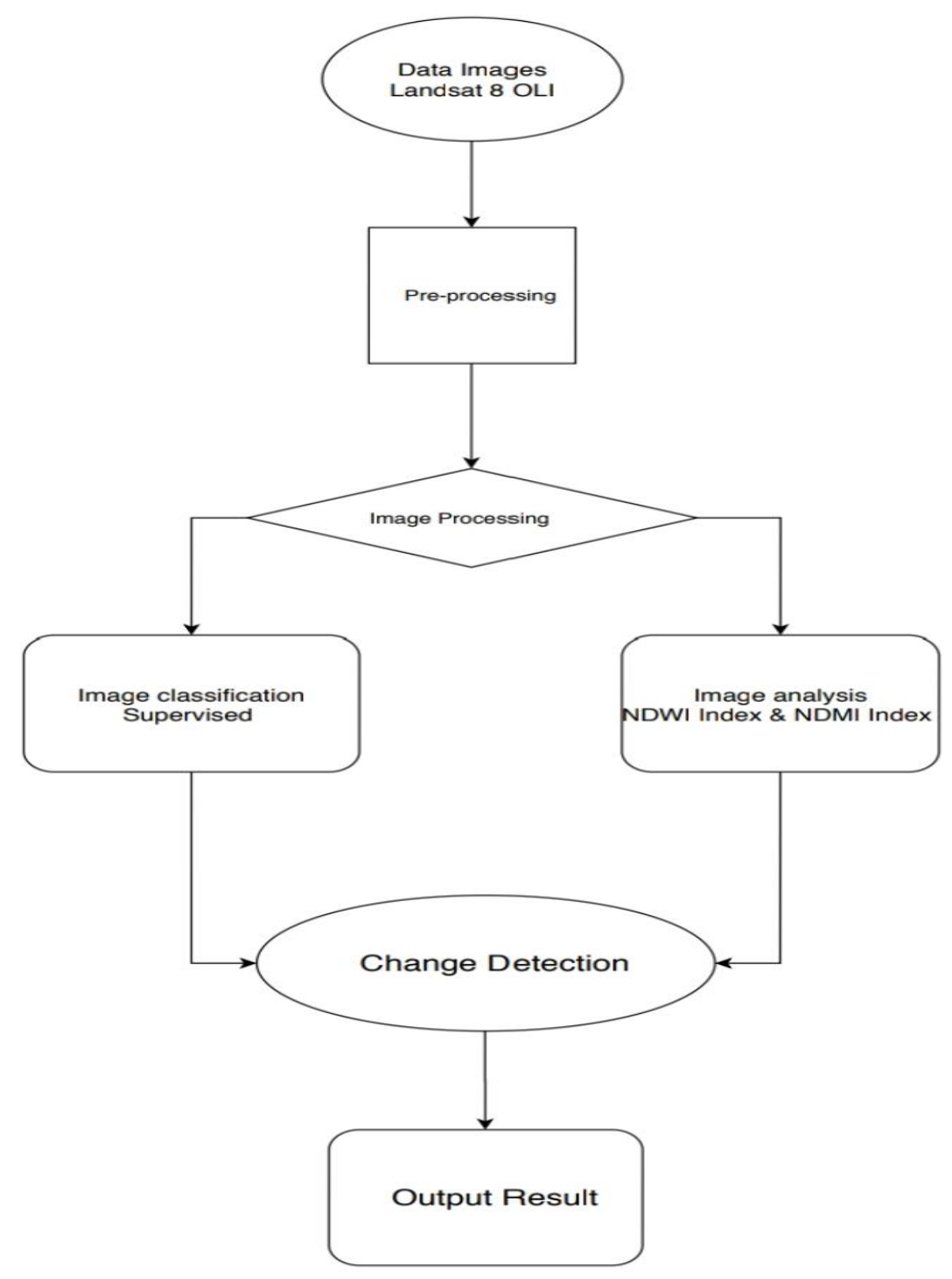

Figure 2-The block diagram of the current research work.

\section{Results, discussion, and conclusions}

\subsection{Image Color Components}

A real or natural color composite is an image that shows the visible ranges of the green, red, and blue colors for the green, red, and blue channels that meets computer screen. The produced component can be observed by human eye naturally; the plant cover appears in green, the water appears in dark blue to black, the earth appears as naked, and the not enforced surfaces appear in light gray and brown. Many people prefer the real color combination, because it looks real and normal to our eyes, but it is hard to recognize the precise changes in the features. The pictures with natural colors can have low contrast and appear as foggy because of dispersion of blue color in the atmosphere. 


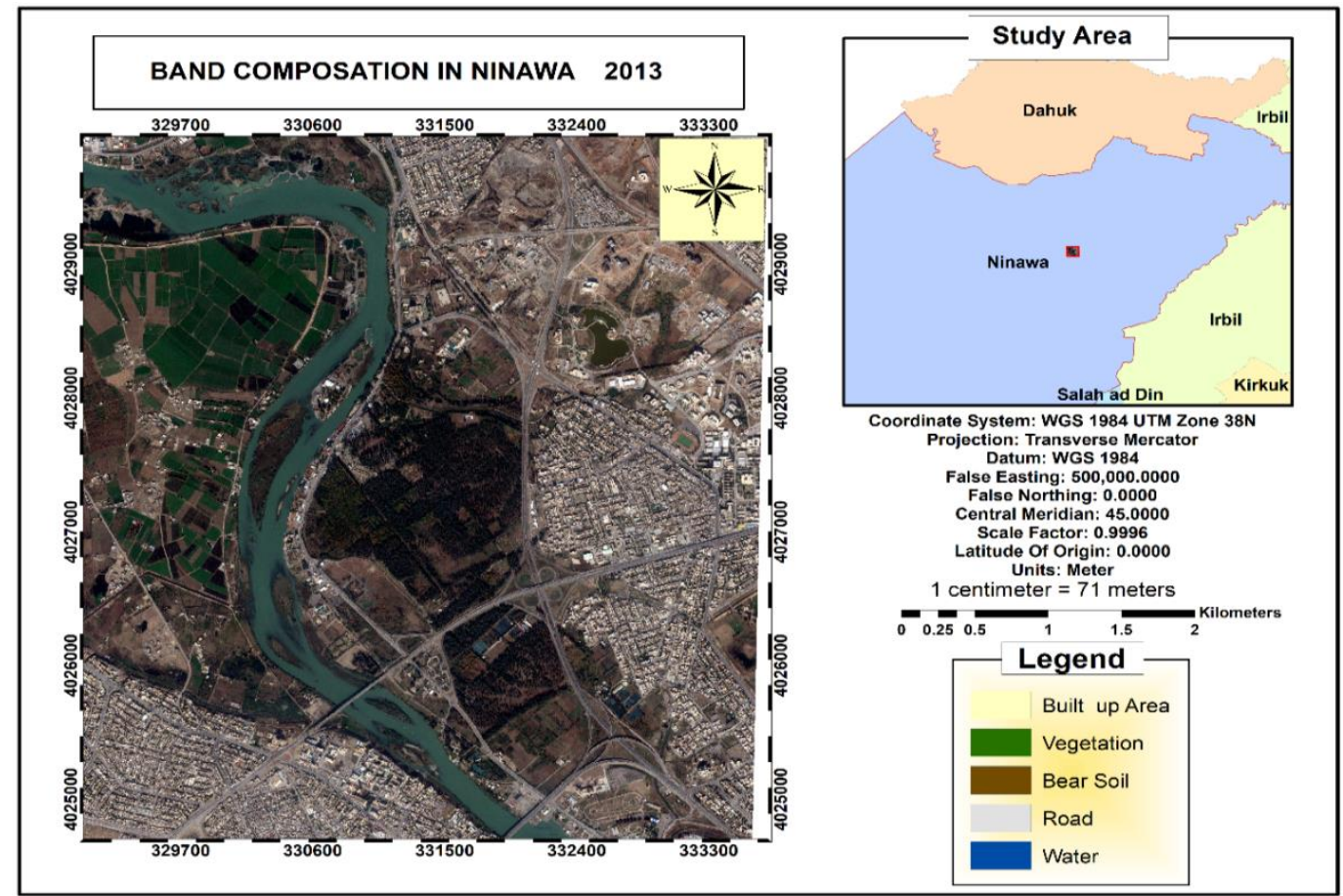

(a)

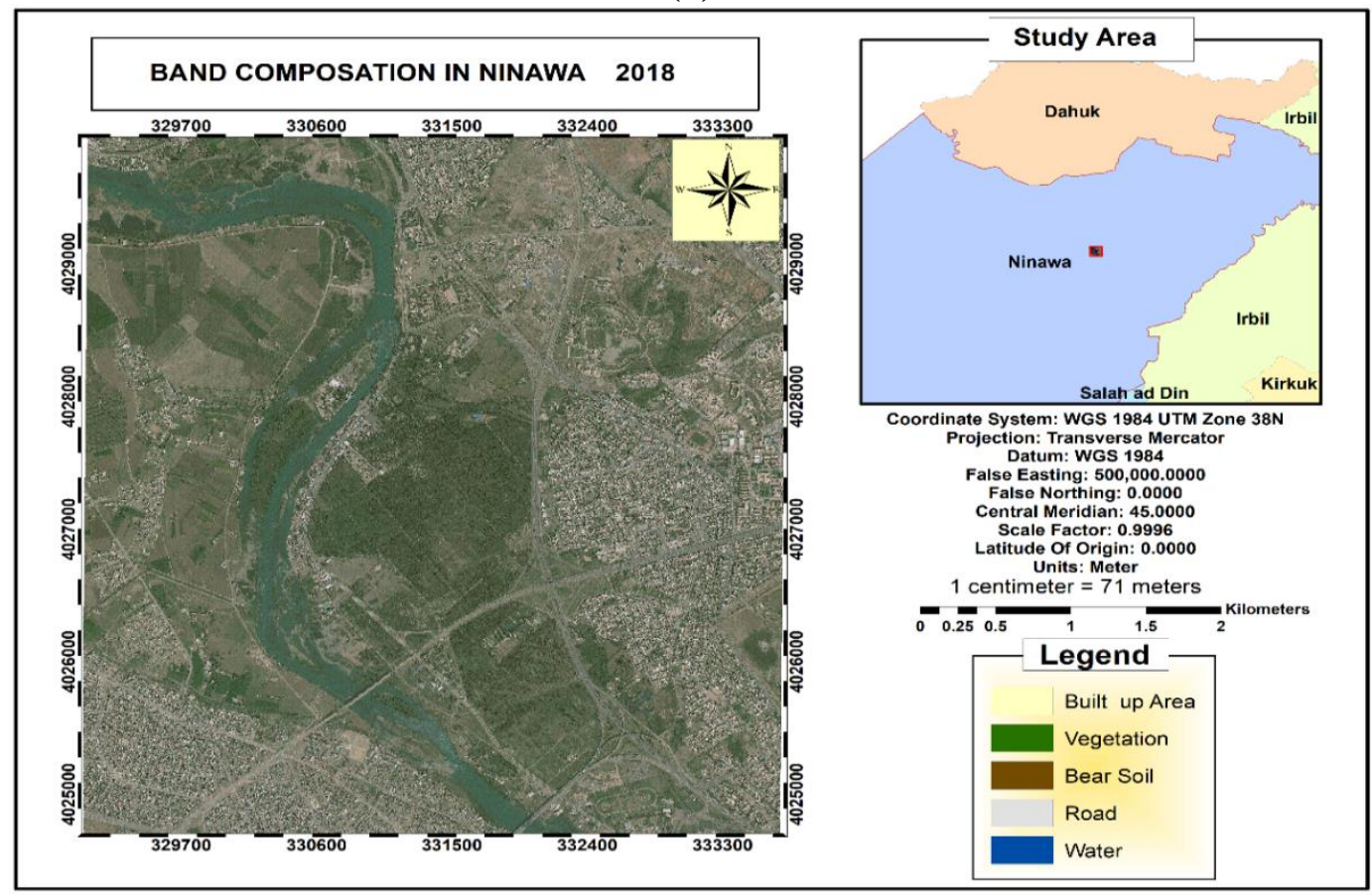

(b)

Figure 3-Al Mawsil (Mosul) forest Composition of the band (a) 2013, (b) 2018.

\subsection{Water Index}

\section{a. Normalized Difference Water Index}

NDWI is a useful tool in drawing water body maps. Water surfaces absorb the infrared visible light in the electromagnetic spectrum. The nearby green and infrared ranges of NDWI are used to highlight water bodies. This index is sensitive to built-up lands and might lead to overestimation of water surfaces. Green wavelengths and NIR are used to monitor changes inside water surfaces.

$$
\text { NDWI }=(\text { Green }- \text { Near Infrared }) /(\text { Green }+ \text { Near Infrared })
$$


Figure 4 shows the NDWI results for Ninawa governorate, including Mosul city, in 2013 and 2018.

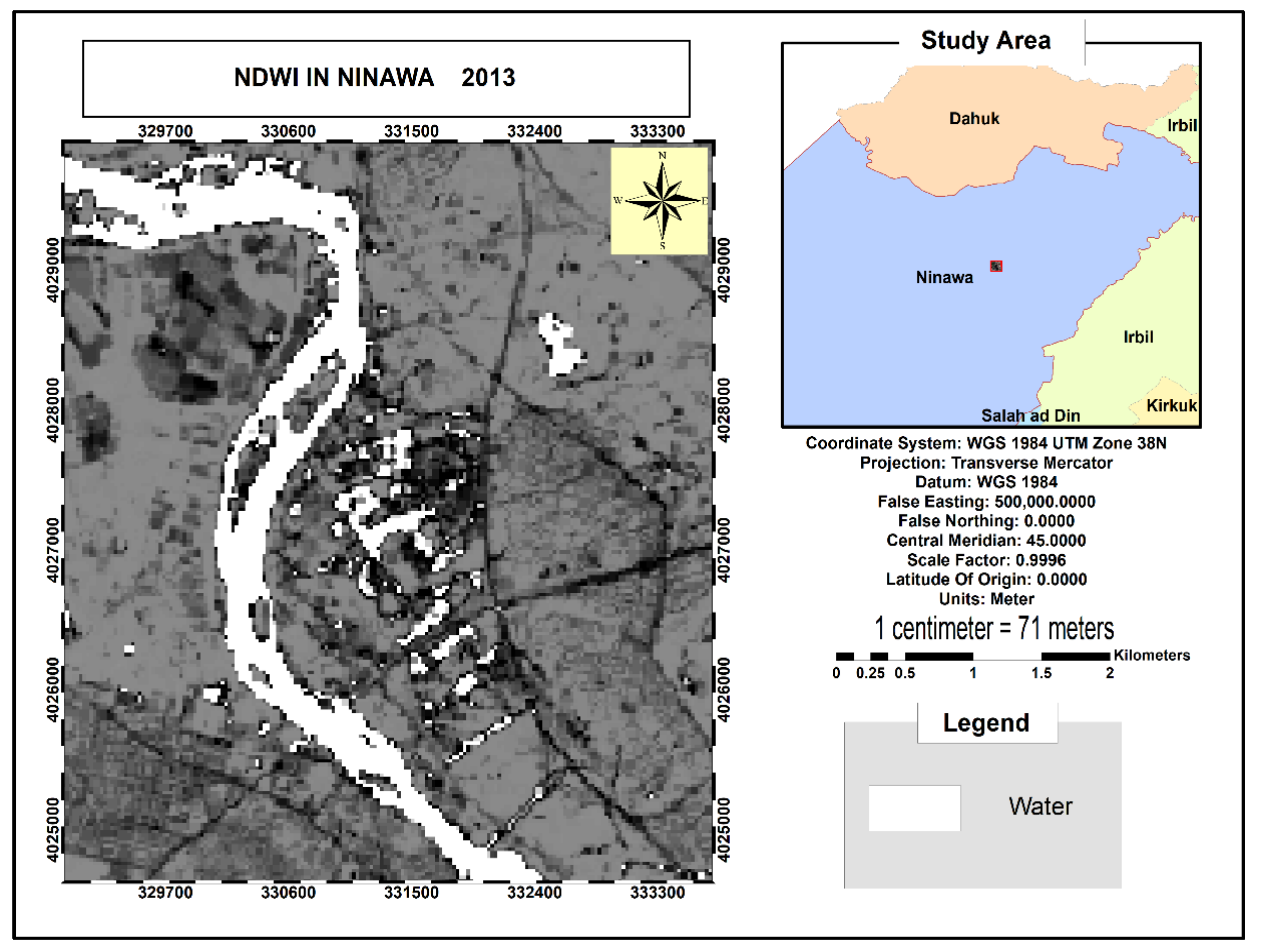

(a)

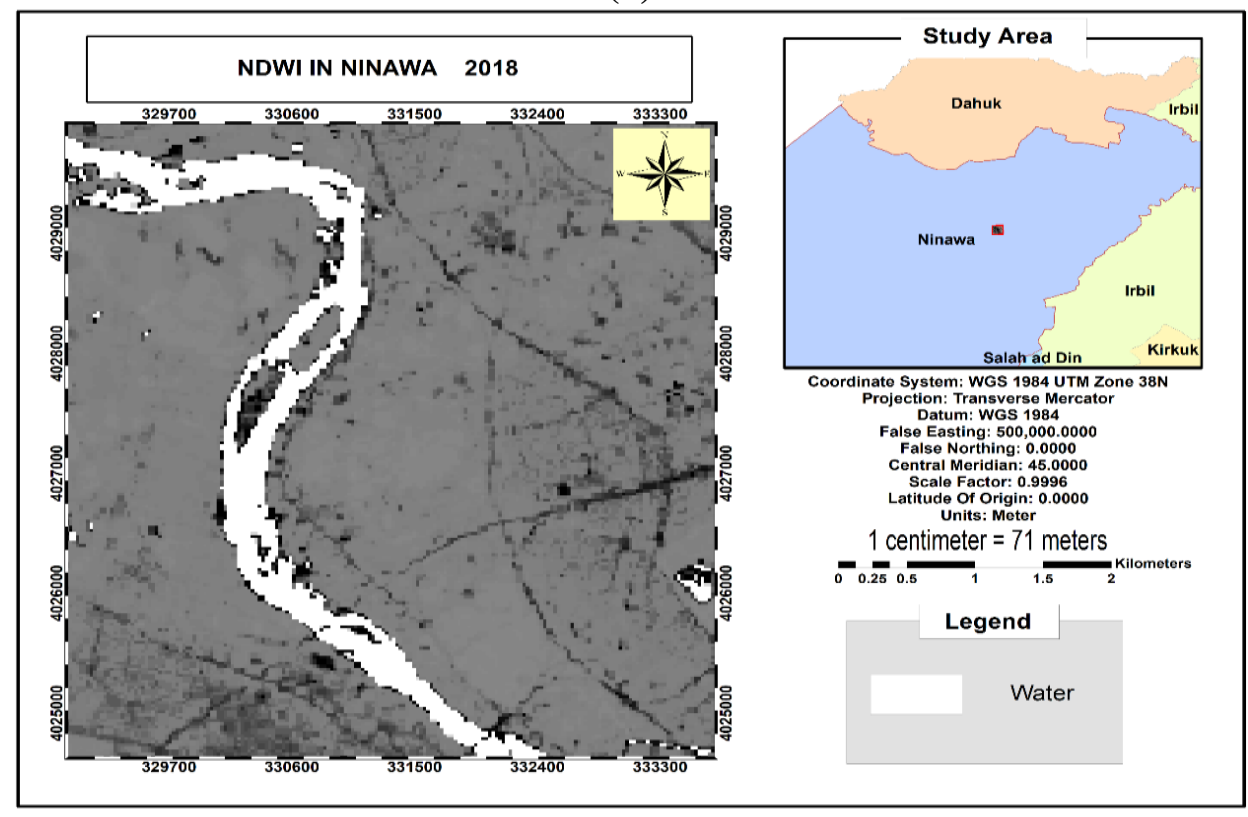

(b)

Figure 4-NDWI results for Ninawa Governorate: (a) 2013, (b) 2018.

\section{b. Normalized Difference Moisture Index}

NDMI can be calculated using parameters of light measured using a sensor that contains a beam of light that ranges from near infrared to short waves. It is at least as precise to detect forest type and density disturbance in similar biomes of a specific forest, especially when taking Landsat images with time difference of less than 2 years. The NDMI value can be calculated using the following equation: 
Figure 5 shows the NDMI for Ninawa governorate, including Mosul city in 2013 and 2018.

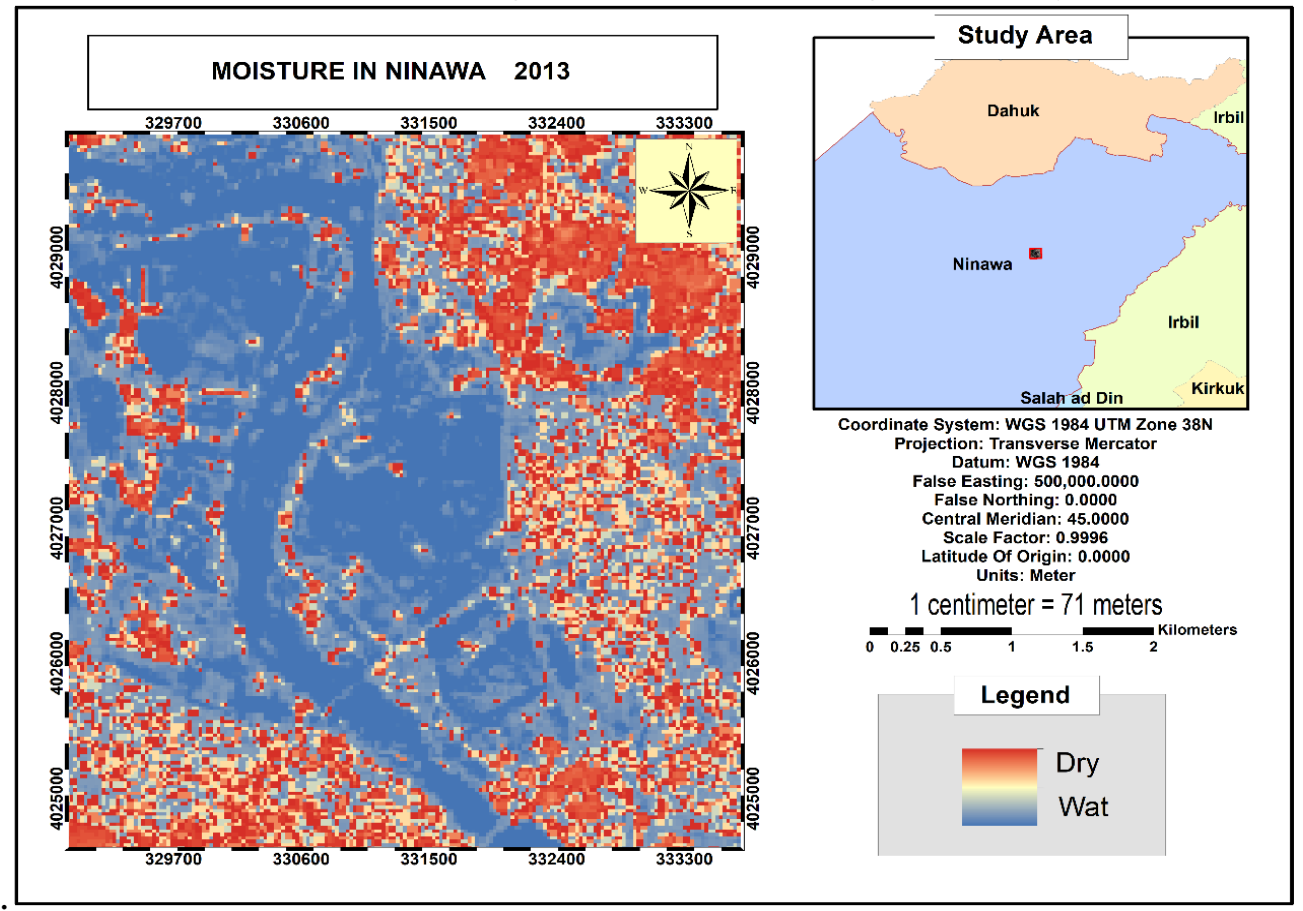

(a)

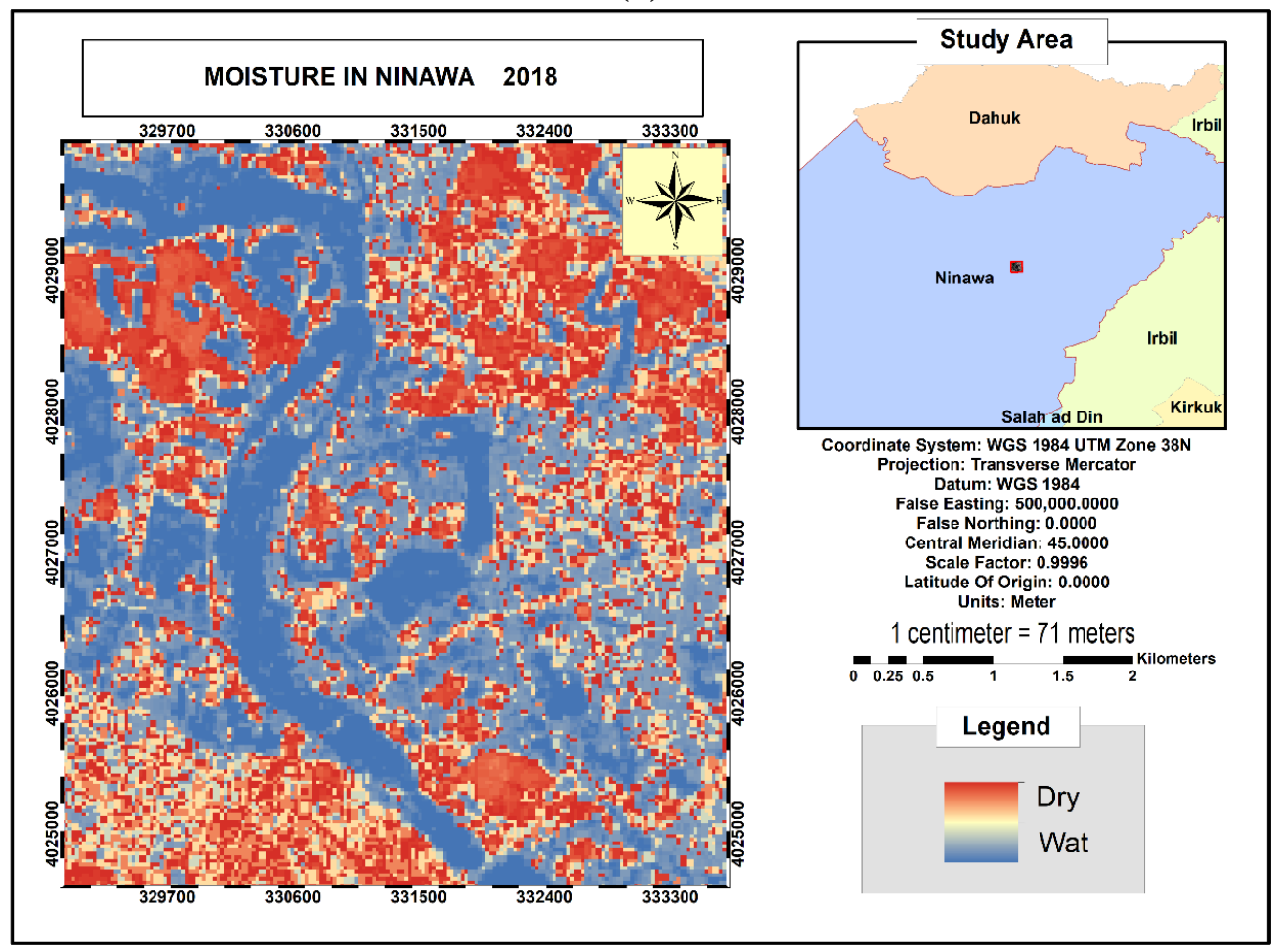

(b)

Figure 5-NDMI values for Ninawa Governorate, (a) 2013, (b) 2018. Dry (Dray land), Wat (water). 


\subsection{Image classification}

Image classification is the process of obtaining categories of information, such as land cover categories, from extracted multi-spectral images used in remote sensing. The workflow is conducted through multiple steps to progress from preprocessing to segmentation and then training, classification, evaluation, and précising. Each step may be iterative and the process requires in-depth knowledge of input images, schema, classification methods, and also expected results and acceptable accuracy [13]. There are two types of classification, unsupervised and supervised. In the current research, the supervised method is adopted. In the supervised classification method, the result of rating depends on accreditation of training samples. The training modules represent sites for all categories in the image. These locations are stored either as points or squares with the category names of each location. It is created or selected based on knowledge of the data used from the source and the expected results Depending on the training modules, all other pixels in the image are classified, which is the default choice. Figure 6 shows the results of the supervised classification for the study area in 2013 and 2018.

\subsection{Change detection}

Change detection is a process which measures the changed attributes of a particular region between two or more periods of time [14]. It is often a comparison of satellite or aerial images of the same area that has been taken for different time periods. This process is linked to natural resource management, environmental monitoring, or urban development measurement Figure 7-a shows the block diagram of the current research work. Figure 7-b shows a composite of the bands of 2013 and 2018.

\section{Change Detection}

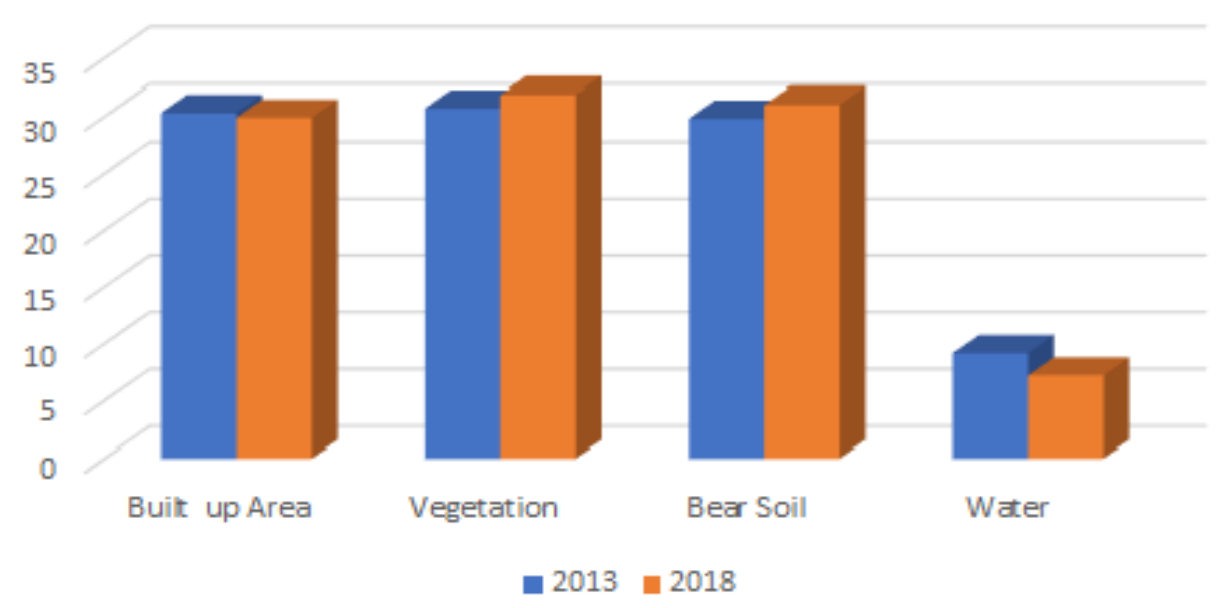

Figure 6-Histogram of Change Detection of Ninawa

Table 2- Change detection rate

\begin{tabular}{|c|c|c|c|}
\hline & $\mathbf{2 0 1 3}$ & $\mathbf{2 0 1 8}$ & Rate of Change \\
\hline Built up Area & $30 \%$ & $30 \%$ & $0 \%$ \\
\hline Vegetation & $31 \%$ & $32 \%$ & $1 \%$ \\
\hline Barren Land & $30 \%$ & $31 \%$ & $1 \%$ \\
\hline Water & $9 \%$ & $7 \%$ & $-2 \%$ \\
\hline
\end{tabular}




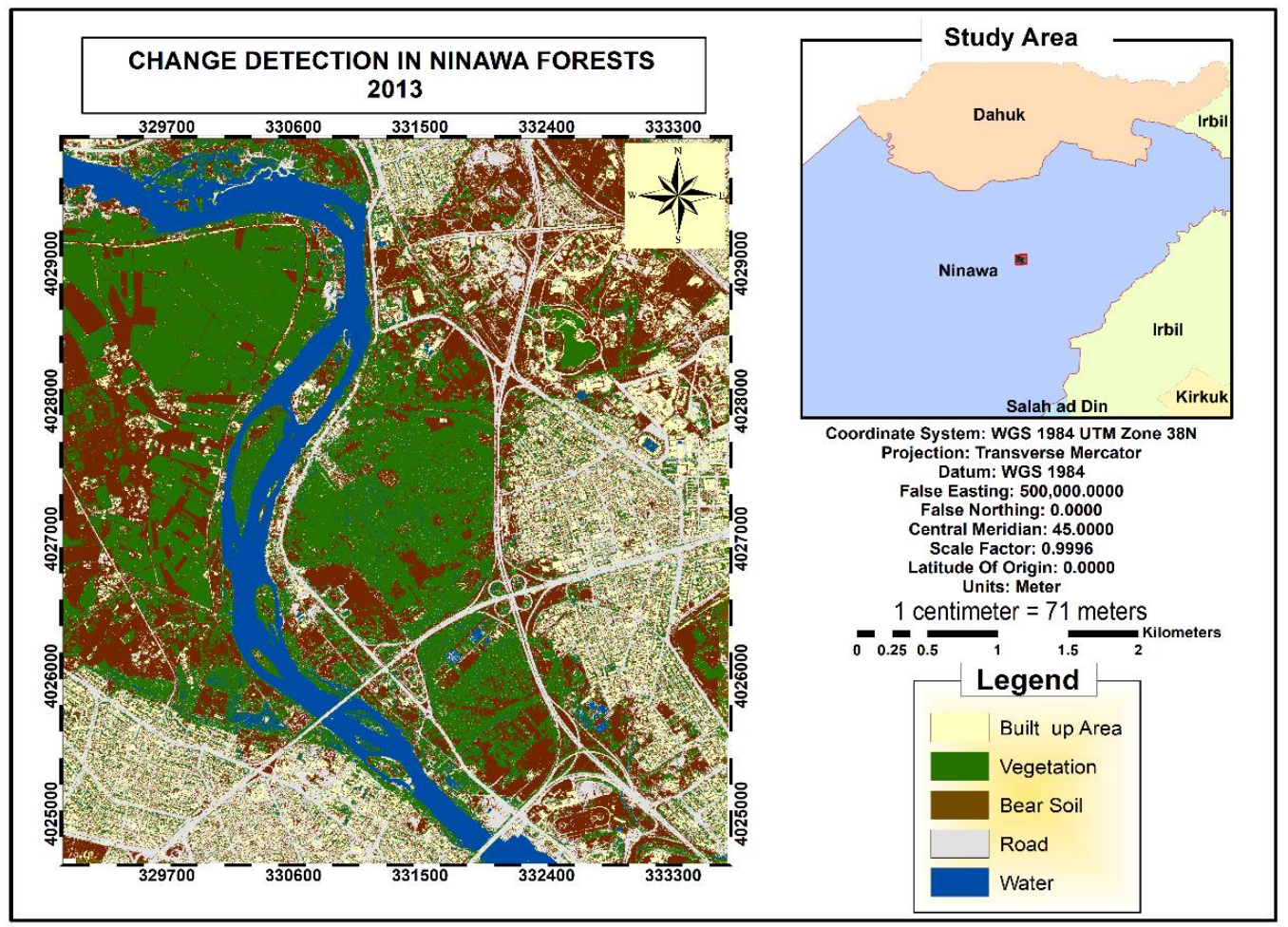

Figure 7- (a) Supervised Classification (2013)

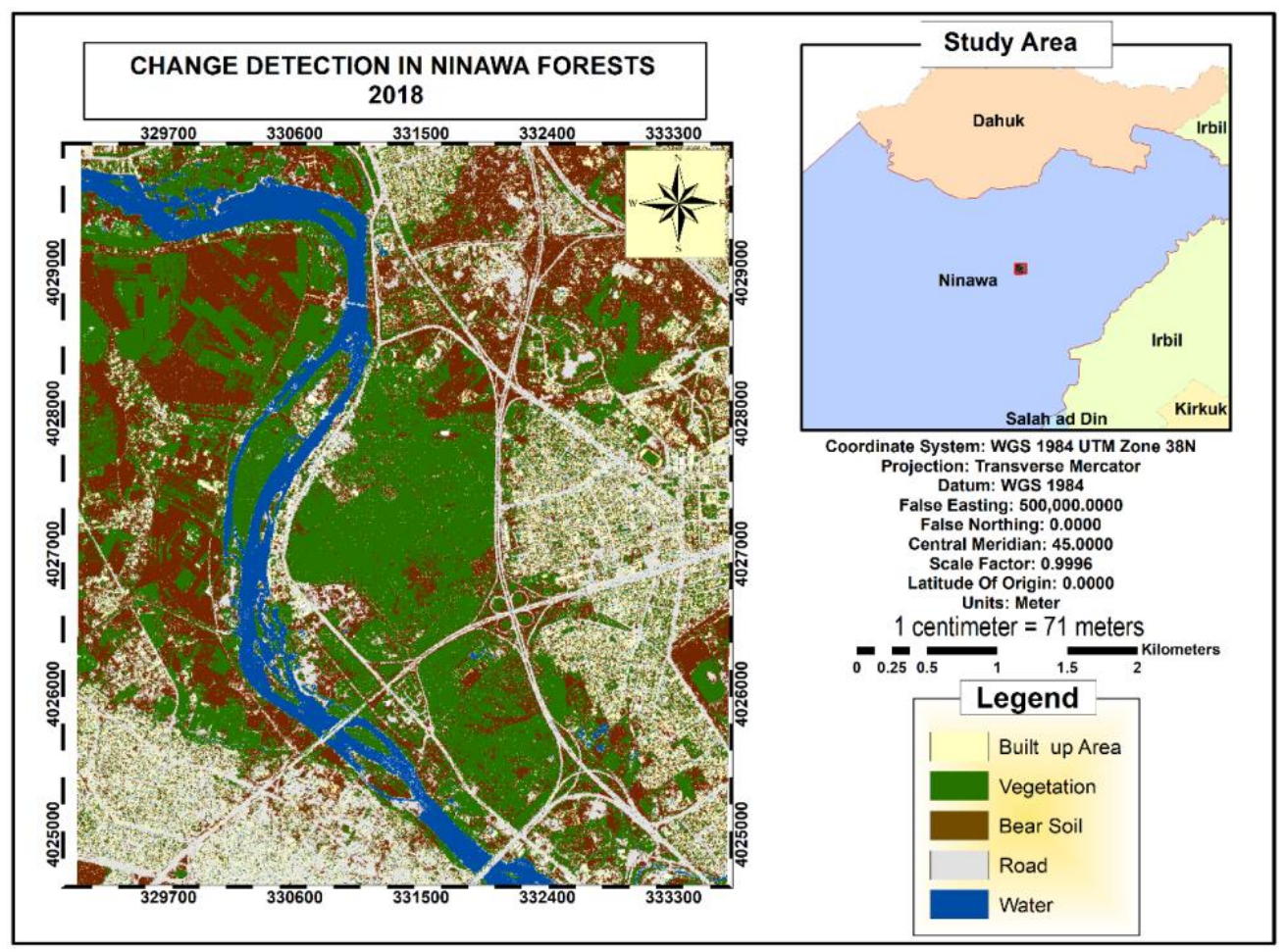

Figure 7- (b) Supervised Classification (2018)

\subsection{Conclusions}

This paper focuses on land use/land cover changes in Mosel forest area, using remote sensing data and GIS technology. Our results clearly show that land use/land cover changes were significant during the period from 2013 to 2018. There was a significant expansion of built-up areas. On the other hand, there was a decrease in agricultural, water, and forest areas. This study clearly indicates the significant impact of population and its development activities on 
land use/land cover change. It proves that that integration of GIS and remote sensing technologies is an effective tool for urban planning and management. The quantification of land use/land cover changes of forest areas is very useful for environmental managers, policy makers, and the public to better understand the environment.

\section{References}

[1] M. A. Ahmed and W. A. Ahmad, "Using Normalized Difference Vegetation Index (Ndvi) To Assessment The Changes Of Vegetations Cover In Surrounding Area Of Himreen Lake", Iraqi Journal of Science, vol. 54, no.4, pp. 895-901, 2013.

[2] Israa J. Muhsin, "Change detection of remotely sensed image using NDVI subtractive and classification methods", Iraqi Journal of Physics, vol.14, no.29, pp. 125-137, 2016.

[3] Israa J. M. \& Amjed H. M., "Detecting and Monitoring the Vegetal Cover of Karbala Province (Iraq) Using Change Detection Methods", Iraqi Journal of Science, vol. 58, no.3A, pp. 1345-1354, 2017.

[4] Faisel G. Mohammed, "Optimal Palette Create with the Specified Number of Colors Using Octree Quantization”, Iraqi Journal of Science, vol.53, no.3, pp. 677-682, 2012.

[5] Faisel G. Mohammed, "Satellite Image Gap Filling Technique", Iraqi Journal of Science, vol. 53, no. 4, pp. 1232-1235, 2012.

[6] Sobhan, I., Alam, A.B.M.S., Chowdhury, M.S.M., Biodiversity of Tanguar Haor: A Ramsar Site of Bangladesh, Volume II: Flora. IUCN Bangladesh Country Office. Dhaka, Bangladesh, 2012, pp. xii+236.

[7] Steven E. Franklin, Remote Sensing for Sustainable Forest Management. CRC press LLC. 2001, 448p.

GoogleMap

https://www.google.com/maps/place/The+Forest+\%2F+Mosul+Park,+\%D8\%A7\%D9\%8 4\%D9\%85\%D9\%88\%D8\%B5\%D9\%84\%E2\%80\%AD/@36.3705712,43.1385065,5118 $\underline{\mathrm{m} / \text { data }=! 3 \mathrm{~m} 2 ! 1 \mathrm{e} 3 ! 4 \mathrm{~b} 1 ! 4 \mathrm{~m} 5 ! 3 \mathrm{~m} 4 ! 1 \mathrm{~s} 0 \times 400794 \mathrm{~d} 31 \text { ceef741:0x300863b0aa21be64!8m2!3d }}$ 36.364739!4d43.1187979?hl=ar

[8] Md. Inzamul Haque, Rony Basak, Land cover change detection using GIS and remote sensing techniques: Aspatio-temporal study on Tanguar Haor, Sunamganj, Bangladesh, vol. 20, pp. 251-263, 2017.

[9] 1-Ali Al-Taie - Mosul Tourist Forest A copy saved December 22, 2017 on the Wayback Machine.

[10] News - Pictures .. Mosul's forests after the fire. A copy saved December 16, 2019 on the Wayback Machine

[11] Franklin, S.C and D.R. Peddle, "Spectral Texture for Improved Classification in Complex Terrain”. Int. J. Remote Sensing. vol. 10, no. 8, 1989.

[12] Tiwari, A.K., Kudrat, M. and Bhan, S.K. (1990)

[13] Vegetation Cover Classification in Sriska National Park and Surrounding. J. Indian Soc. Remote Sensing, vol. 18, pp. 43-5.

[14] Rao, D.P., IRS IA Application for Land use / Land Cover Mapping in India. Current Science, pp.153-167, 1991. 